\title{
Cyclone contribution to the Mediterranean Sea water budget
}

\author{
E. Flaounas $^{1} \cdot$ A. Di Luca ${ }^{1,6} \cdot$ P. Drobinski $^{1} \cdot$ S. Mailler $^{1} \cdot$ T. Arsouze $^{2} \cdot$ S. Bastin $^{3}$ \\ K. Beranger ${ }^{2,4}$ C. Lebeaupin Brossier ${ }^{5}$
}

\begin{abstract}
This paper analyzes the impact of cyclones to the atmospheric components on the Mediterranean Sea Water Budget, namely the cyclones contribution to precipitation and evaporation over the Mediterranean Sea. Three regional simulations were performed with the WRF model for the period 1989-2008. The model was run (1) as a standalone model, (2) coupled with the oceanic model NEMOMED12 and (3) forced by the smoothed Sea Surface Temperature (SST) fields from the second simulation. Cyclones were tracked in all simulations, and their contribution to the total rainfall and evaporation was quantified. Results show that cyclones are mainly associated with extreme precipitation, representing more than $50 \%$ of the annual rainfall over the Mediterranean Sea. On the other hand, we found that cyclone-induced evaporation represents only a small fraction of the annual total, except in winter, when the most intense Mediterranean cyclones take place. Despite the significant contribution of cyclones to rainfall, our results show that there is a balance between cyclone-induced
\end{abstract}

E. Flaounas

flaounas@1md.polytechnique.fr

1 Institut Pierre Simon Laplace/LaBoratoire de Météorologie Dynamique, CNRS and Ecole Polytechnique, Palaiseau, France

2 ENSTA-ParisTech, 91362 Palaiseau, France

3 Institut Pierre Simon Laplace/LaBoratoire Atmosphères, Milieux, Observations Spatiales, CNRS and Université Versailles Saint Quentin, Guyancourt, France

4 Laboratoire d'Etude des Transferts en Hydrologie, Université Grenoble-Alpes, 38000 Grenoble, France

5 CNRM-GAME, Météo-France and CNRS, Toulouse, France

6 Climate Change Research Centre, University of New South Wales, Sydney, Australia rainfall and evaporation, suggesting a weak net impact of cyclones on the Mediterranean Sea water budget. The sensitivity of our results with respect to rapid SST changes during the development of cyclones was also investigated. Both rainfall and evaporation are affected in correlation with the SST response to the atmosphere. In fact, air feedbacks to the Mediterranean Sea during the cyclones occurrence were shown to cool down the SST and consequently to reduce rainfall and evaporation at the proximity of cyclone centers.

\section{Introduction}

The Mediterranean region is located between the dry and arid region of North Africa and the storm-tracks of the mid-latitudes of Northern Europe. In this transition zone the Mediterranean climate is highly controlled by its most prominent geographical feature, the Mediterranean Sea. The Mediterranean Sea Water Budget (MSWB) refers to the compensation between the temporal rate of change of the Mediterranean Sea water mass due to large evaporation and the water gain through straits, rivers and precipitation. The MSWB is of equal interest to both the marine environment and the regional climate. For instance, the MSWB controls (or affects) the thermohaline circulation (Marshall and Schott 1999; Millot and Taupier-Letage 2005). Besides this effect at basin-scale, air-sea interactions through evaporation and precipitation also affect the locally generated weather systems by inducing Sea Surface temperature (SST) fluctuations (Lebeaupin Brossier et al. 2013; Berthou et al. 2014).

The MSWB is modulated by several factors, according to the following equation (e.g. Mariotti et al. 2002; Dubois et al. 2012): 
$\mathrm{MSWB}=\mathrm{P}-\mathrm{E}+\mathrm{R}+\mathrm{A}+\mathrm{B}$

where $\mathbf{E}$ stands for evaporation, $\mathbf{P}$ for precipitation, $\mathbf{R}$ for the river runoff, $\mathbf{A}$ for the water inflow and outflow from or to the Atlantic Ocean and $\mathbf{B}$, the water inflow and outflow from or to the Black Sea. Scale analysis of Eq. 1 reveals that the main modulators at short-range of the MSWB are the atmospherically induced freshwater fluxes due to evaporation and precipitation, while in long term, the influx of seawater from the Atlantic (A) keeps constant the water mass of the Mediterranean Sea.

The precise quantification of evaporation and rainfall is a rather difficult task due to the sparseness of the observations, as also due to the difficulty of collecting in situ measurements over the sea. Therefore, their estimation relies on the use of models, reanalyses and indirect estimations and is hence subject to uncertainties due to the significant impact of the physical parameterizations on the results (Mariotti 2010; Dubois et al. 2012; Di Luca et al. 2014). Synthesizing the results of several studies (e.g. Romanou et al. 2010; Sanchez-Gomez et al. 2011), the estimated annual evaporation over the Mediterranean Sea is of the order of $900-1500 \mathrm{~mm}$ and the total precipitation is of the order of 300-700 mm per year. Despite the high variability of these estimations, all studies present a fairly robust estimation of evaporation minus precipitation $(\mathrm{E}-\mathrm{P})$ annual mean values that vary from 700 to $1000 \mathrm{~mm}$ per year thus suggesting a net freshwater flux from the Mediterranean Sea towards the atmosphere.

In this paper we analyze the spatial and temporal variability of the atmospheric freshwater fluxes over the Mediterranean Sea (evaporation and rainfall) from the perspective of cyclonic atmospheric systems. Cyclones-related strong winds are expected to affect evaporation and the formation of deep water masses in the Mediterranean Sea (Romanski et al. 2012), while their associated rainfall extremes are potentially a sub-regional significant source of freshwater into the Mediterranean Sea. Indeed, Mediterranean cyclones are the most prominent meso-scale atmospheric systems which often develop into high impact weather, provoking rainfall extremes and windstorms. Climatological studies show that the most intense cyclones occur during winter and mainly over the Mediterranean Sea. In particular, they form over the leeward side of the Alps Mountains, over the Adriatic and the Ionian Seas and over the western Mediterranean (e.g. Trigo et al. 2002; Flocas et al. 2010; Campins et al. 2011; Flaounas et al. 2014a). In these regions, observations of deep convection are shown to match the cyclone tracks, suggesting a strong connection between the two (Claud et al. 2012).

The strong contribution of cyclones to the total rainfall over the Mediterranean region has been highlighted in many past studies. For instance, Jansa et al. (2001) detected and quantified the cyclones contribution to extreme rainfall over the western Mediterranean. Based on observations and reanalyses, the authors showed that $90 \%$ of the cases of extreme rainfall (rain rates greater than $60 \mathrm{~mm} \mathrm{~h}^{-1}$ ) can be attributed to cyclonic systems. In a more recent study, Hawcroft et al. (2012) used 30 years of data from reanalysis and satellite products to quantify the contribution of extratropical cyclones to the precipitation climatology in the Northern Hemisphere. The authors showed that the storms contribution to the total winter precipitation over the Mediterranean region might vary between 70 and $90 \%$, depending on the area. In similar studies, Catto and Pfahl (2013) and Pfahl et al. (2014) used reanalyses in order to quantify the fronts and warm conveyor belts (sharply ascending air masses over the warm front of extra-tropical cyclones) contribution to the rainfall extremes, respectively. Results show that cyclones over the Mediterranean may account for more than $70 \%$ of the total rainfall extreme events.

Concerning evaporation little has been written on the contribution of Mediterranean cyclones. However, it has been shown that cyclones are the main actors of windstorms in the region and consequently they are expected to have a strong impact on evaporation. For instance, Nissen et al. $(2010,2013)$ used the ERA-40 reanalyses to track Mediterranean cyclones and showed that wind extremes in the region (defined as the 98th percentile of a grid point's wind speed) were found to be related to cyclonic systems evolving over the Mediterranean Sea basin. The development of Mediterranean cyclones leads to intense air-sea interactions (Emanuel 2005) that locally modify the SST and thus eventually alter the subsequent development of the cyclone. Indeed, numerical experiments on cyclone dynamics have shown that forcing the simulations with warmer SSTs could reinforce significantly the Mediterranean cyclones intensity (Homar et al. 2003; Miglietta et al. 2011; Katsafados et al. 2011). In this context the use of atmosphere-ocean coupled modeling systems appear to be essential to realistically represent the dynamics of intense cyclones (Akthar et al. 2014).

Our analysis is complementary to, and extends the results of Lebeaupin Brossier et al. (2014) who recently showed that rainfall and evaporation extremes over the sea contribute by approximately 22 to $30 \%$ to their annual totals. Focusing on cyclones, our objective is twofold: (1) to quantify the Mediterranean cyclone-induced rainfall, evaporation and their sensitivity to air-sea feedbacks; (2) to quantify the cyclones contribution to the atmospheric components of the MSWB (i.e. to E - P). To meet the above purposes, we use three 20-year simulations (19892008) performed with the MORCE-Med system (Drobinski et al. 2012) at a horizontal resolution of $20 \mathrm{~km}$ in the frame of HyMeX (Hydrological cycle in the Mediterranean Experiment; Drobinski et al. 2013) and MED-CORDEX 
Table 1 Simulations descriptions

\begin{tabular}{ll}
\hline WRF atmospheric simulations & Description \\
\hline SimREF & SST forced toWRF by ERA-Interim \\
SimCPL & $\begin{array}{c}\text { SST explicitly resolved by the NEMO-MED12 oceanic model and given on-line to WRF each } 3 \text { h (two-way } \\
\text { interactive coupling) }\end{array}$ \\
SimSMO & SST forced to WRF by the outputs of SimCPL after applying a 31-day moving average to each grid point \\
\hline
\end{tabular}

(COordinated Regional climate Downscaling Experiment for the Mediterranean; Ruti et al. 2015) programs. All simulations share the same atmospheric model and the same atmospheric boundary conditions but two have prescribed SST whereas one is coupled to an oceanic model.

In Sect. 2, we describe our methodology. In Sect. 3, we present the 20-year cyclone climatology for the three simulations, while in Sects. 4 and 5 we quantify the cyclones contribution to rainfall, evaporation and to the MSWB. Finally, in Sect. 6 we provide a discussion of our results, as well as our work's conclusion.

\section{Methodology}

\subsection{Models and simulations}

In order to assess the sensitivity of Mediterranean cyclones to the SST, as also their contribution to the MSWB, we use the outputs from three regional climate simulations, performed with the Weather Research and Forecasting (WRF; Skamarock and Klemp 2008) model in the context of MED-CORDEX (COordinated Regional climate Downscaling Experiment for the Mediterranean domain; Ruti et al. 2015) and HyMeX (Hydrological cycle in the Mediterranean Experiment; Drobinski et al. 2014). All simulations share the same domain that covers the whole Mediterranean region at a horizontal resolution of $20 \mathrm{~km}$, and 28 vertical levels. The simulations are driven by the ERA-Interim reanalyses (Dee et al. 2011) at the resolution of $0.75^{\circ} \times 0.75^{\circ}$ in longitude and latitude, for the period 1989-2008. The outputs are available at a $3 \mathrm{~h}$ time interval. Grid nudging is applied in all simulations using a $6 \mathrm{~h}$ relaxation time (Salameh et al. 2010; Omrani et al. 2013) on horizontal wind, temperature and water vapor, only above the planetary boundary layer. For all model integrations we used the same physical parameterizations: the Kain-Fritsch convection scheme (Kain 2004), the thermal diffusion land surface model, the WSM5 microphysics scheme (Hong et al. 2004) and the RRTMG longwave and shortwave radiation scheme (Clough et al. 2005).

The reference simulation (SimREF) is forced by 6-hourly SST fields from the ERAI-Interim reanalysis. The coupled simulation (SimCPL) runs with two-way interactive exchanges between WRF and NEMO-MED12 models, managed by the OASIS coupler version 3 with a frequency of $3 \mathrm{~h}$ (see details in Drobinski et al. 2012; Lebeaupin Brossier et al. 2013, 2014). The NEMOMED12 model (Lebeaupin Brossier et al. 2011; Beuvier et al. 2012) has a horizontal resolution of $1 / 12^{\circ}(\sim 7 \mathrm{~km})$ and 50 stretched vertical z-levels. The exchanged variables between the two models are SST, the heat, water and momentum fluxes. The coupler uses a bilinear method to interpolate the ocean grid towards the atmospheric grid and vice versa (Lebeaupin Brossier et al. 2013, 2014).

Finally, the smoothed simulation (SimSMO) is an atmosphere-only simulation with the same characteristics as SimREF, except that the forced SST to the model corresponds to the temporally smoothed SST outputs from SimCPL. This forcing has been designed in order to retain the same climatology and diurnal cycle as the SST of the SimCPL simulation, but without the sub-monthly SST variations. To this end, the SST value used to force the SimSMO atmospheric simulation at each target time step was calculated by performing a central moving average with a 31 day window, retaining only the time differing from the target time step by an entire number of days, so that only times with the same GMT hour are averaged together. This precaution is take in order to preserve the diurnal cycle of the SST in simSMO. In this way, the SST diurnal cycle, its seasonal variations, as well as all the persistent spatial structures that exist in the SimCPL run are preserved in SimSMO. On the other hand, the high-frequency air-sea coupling effects (sub monthly variations) are suppressed. Table 1 shows a summary of the three simulations.

Lebeaupin Brossier et al. (2014) compared the SST fields of SimREF, derived and forced to WRF by ERAInterim, with satellite observations for the period 19992007 (their Fig. 4). Results show that the ERA-Interim SST fields are in good agreement with the observations, where the climatological bias is less than $0.5^{\circ} \mathrm{C}$, except near the coasts where the bias might reach $1{ }^{\circ} \mathrm{C}$. Figure 1 a shows the 20-year average of the Mediterranean SST used in SimREF, while Fig. 1b shows its difference with the averaged SST simulated by SimCPL. SimCPL presents a bias of $-1{ }^{\circ} \mathrm{C}$, at the western and eastern basins of the Mediterranean Sea, while SimCPL overestimates SST by approximately $+1{ }^{\circ} \mathrm{C}$ at the central Mediterranean. Despite this 

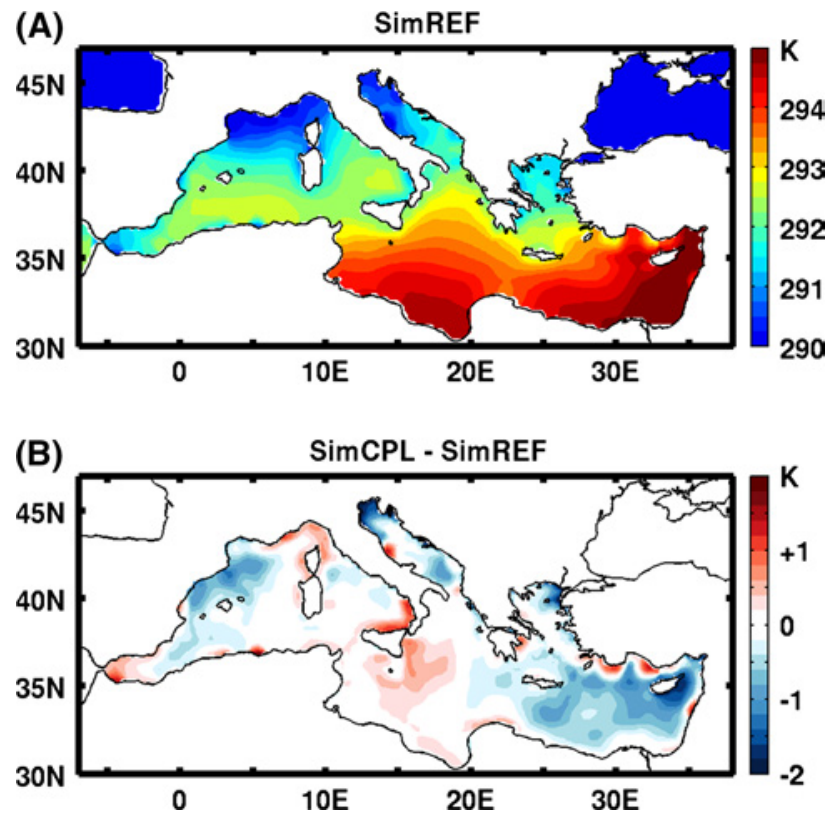

Fig. 1 a SST 20-year average in SimREF. b SST 20-year average differences between SimCPL and SimREF

bias, the added value of SimCPL is that its SST field is in balance with the atmospheric state and circulation, when considering rapid air-sea interactions. Thanks to the high resolution of the ocean compartment model, the SimCPL SST presents also a more realistic spatial variability (Lebeaupin Brossier et al. 2014). It is the air-sea interactions that are tested with SimSMO, where the smoothing operation suppresses their intensity and thus reveals their role on cyclone-induced rainfall and evaporation. Consequently, SimSMO presents the same climatological SST than SimCPL, where differences may become significant only at small temporal and spatial scales.

\subsection{Tracking the Mediterranean cyclones}

\subsubsection{General method}

Tracking Mediterranean cyclones is a complicated issue mainly due to the geographical particularities of the region. Indeed, the Mediterranean is a relatively small region presenting sharp land-sea transitions and high mountains. Orographic pressure lows are quasi constantly present, while relative vorticity maxima might occur frequently due to sharp wind steering. To deal with these issues we apply a complex tracking algorithm, described in detail in Flaounas et al. (2014b), which has been previously calibrated and applied to SimCPL in Flaounas et al. (2014a).

The cyclones tracking method is organized in two steps. In a first step, cyclone centers are located in the 20-year 3-hourly model outputs, defined as relative vorticity local maxima embedded in $850 \mathrm{hPa}$ enclosed contours of $4 \times 10^{-5} \mathrm{~s}^{-1}$. In a second step, the cyclone centers are tracked in time using a low-cost function. This procedure is applied to each detected cyclone as follows: the tracking algorithm first constructs all possible undertaken paths of the cyclones and then selects the one which presents the least average difference of relative vorticity between consecutive track points, weighted by their distance. In this study we retain only cyclone tracks that last at least 1 day (i.e. nine consecutive time steps) and that present maximum intensity of at least $8 \times 10^{-5} \mathrm{~s}^{-1}$ of relative vorticity once at their life time. This threshold has been previously used for the detection of intense Mediterranean cyclones in Flaounas et al. (2013).

In order to quantify the cyclones-induced rainfall and evaporation, we need to define an effective area that is considered to be "under the influence of a cyclone". Hawcroft et al. (2012) used a similar approach defining a circular disk with a radius of a constant length around the center of the tracked cyclones. This radius length was assessed to be $10^{\circ}$ and $12^{\circ}$ for the summer and winter cyclones, respectively. Such a length (about $950 \mathrm{~km}$ ) is excessively long for the relatively weak Mediterranean cyclones (with respect to other extratropical cyclones). In other studies, more "irregular shapes" than a circular disk or different methodologies have been applied. For instance, Flaounas et al. (2013) defined the cyclones effective area by the $3 \times 10^{-5} \mathrm{~s}^{-1}$ enclosed contour of relative vorticity, while Paprtitz et al. (2014) used a scheme where rainfall was attributed to a cyclone if its enclosed contours overlapped with the cyclones center.

In this study, the effective area of the cyclones is depicted by disks whose radii vary dynamically according to the relative vorticity field in the vicinity of the cyclones center. The importance of a dynamically varying cyclone radius has been previously highlighted by Simmonds (2000) who showed that surface cyclonic systems increase their radius as they evolve to their maximum intensity. Our methodology is described in detail and assessed in Flaounas et al. (2014b). The disk's radius has a limit of $1500 \mathrm{~km}$, which is a long distance with respect to the Mediterranean domain, but adequate for capturing the frontal and cyclonic structure of the most intense cyclones, such the January 1995 case (Pytharoulis et al. 2000). The median of all cyclones' effective area is of the order of $500 \mathrm{~km}$, while their 5th and 95th quantile is of the order of 150 and $1050 \mathrm{~km}$, respectively (not shown). The effective area diagnostic is applied to all tracked cyclones in all three simulations in order to determine the grid points affected by cyclones during the whole 20-year period. These grid points are then used as a time variant spatial mask to determine the "cyclonicallyinduced rainfall or evaporation" and the "non-cyclonicallyinduced rainfall and evaporation". 

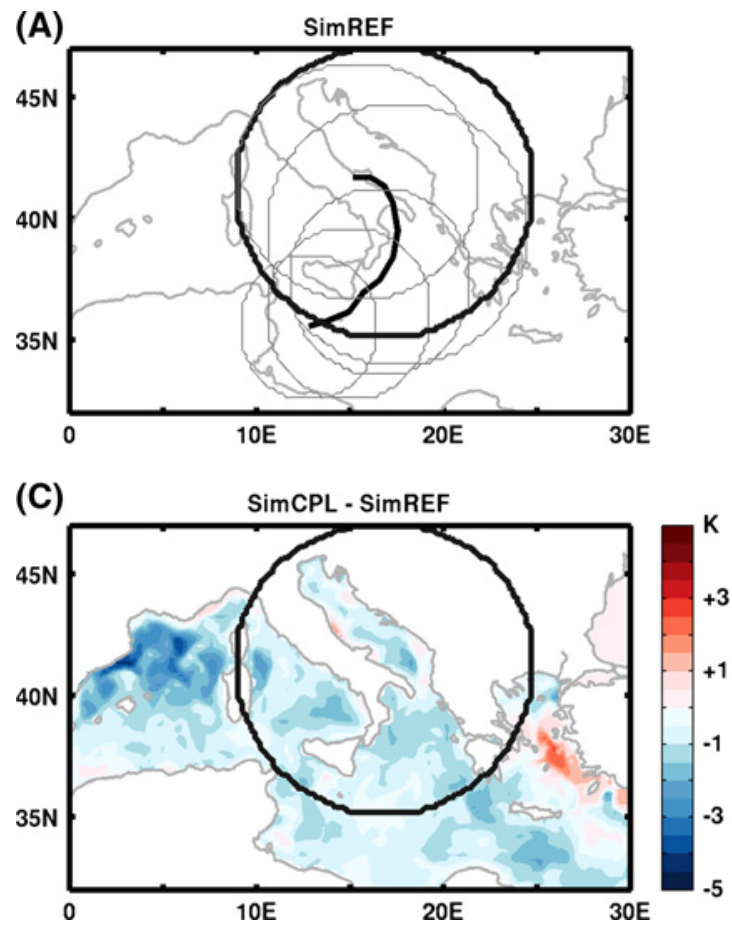

Fig. 2 a Track of the intense cyclone occurring in 24-25 September 2006 (black line) and the cyclone effective area (in circle; black circle depicts the effective area at the mature stage of the cyclone) b SST (in color), wind field at $850 \mathrm{hPa}$ (in arrows) and the cyclone effective

\subsubsection{An example of the applied methodology: the September 2006 case}

As an example, Fig. 2a presents the track and the effective area of an intense Mediterranean cyclone occurring on the 25th September of 2006 (Davolio et al. 2009; Chaboureau et al. 2012), as detected in SimREF. The radius of the circular area around the cyclone's center is proportional to its intensity and clearly grows from the beginning of the track over North Africa until its mature stage over the Italian coast. Figure $2 b$ shows the SST field for SimREF at the timing of the cyclone's maximum intensity (as detected in Fig. 2a) while the SST differences between SimCPL and SimREF are shown in Fig. 2c and the SST differences between SimSMO and SimCPL are shown in Fig. 2d. In Fig. 2b it is noteworthy that the cyclone effective area captures most of the cyclonic circulation at $850 \mathrm{hPa}$. Figure 2c shows that the bias between SimCPL and SimREF is mainly negative. Finally, Fig. $2 d$ shows the effect of fast air-sea feedbacks on the cyclones and the Mediterranean Sea surface. The differences between SimCPL and SimSMO are mainly positive and of small amplitude. These positive anomalies are due to the Mediterranean Sea surface cooling, associated with the strong
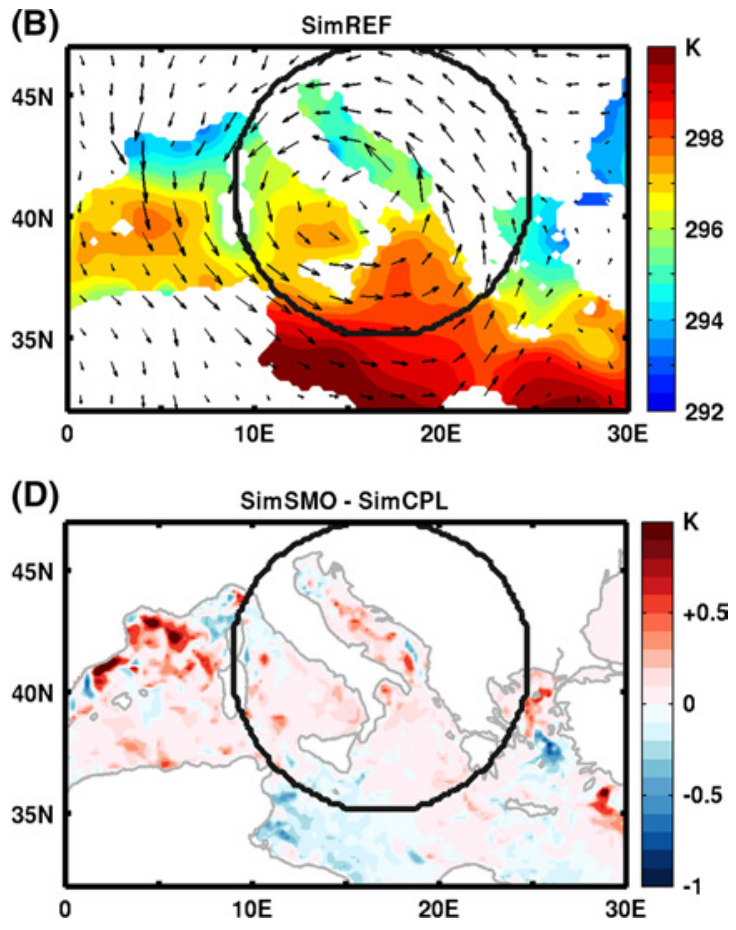

area at the timing of maximum intensity for SimREF. c SST differences of SimCPL minus SimREF. $\mathbf{d}$ As in $\mathbf{c}$ but for SimSMO minus SimCPL

winds and evaporation. Such anomalies are especially evident over the Gulf of Lions where the Mistral wind blows (Lebeaupin Brossier and Drobinski 2009). This suggests that the local SST cooling due to the Mistral wind is suppressed in simSMO as a result of the smoothing operation applied on the SST field.

The SST effect on the September 2006 case is shown in Fig. 3. In SimREF (Fig. 3a), when the cyclone reaches its mature stage, the associated rainband covers the Ionian and the Adriatic Sea with a distinctive center over the Italian coast, where evaporation is also strong and of the order of $10 \mathrm{~mm} \mathrm{~h}^{-1}$. For the same time, Fig. $3 b$ shows that rainfall weakens in SimCPL over the Ionian and the Adriatic Sea, while a dipole of positive and negative anomalies is observed over the Italian coast, at the cyclone center. In agreement with the colder SSTs (Fig. 2c), evaporation in SimCPL becomes weaker. In SimSMO, the filtered SSTs provoke positive evaporation anomalies due to the warmer SST in the area affected by the cyclone. This results in a complex rainfall response with positive and negative anomalies, especially close to the cyclone center. It is noteworthy, that the cyclone effective area includes the whole cyclone-induced rainfall, and also the anomalies due to the different SST forcings in SimCPL and SimSMO. 

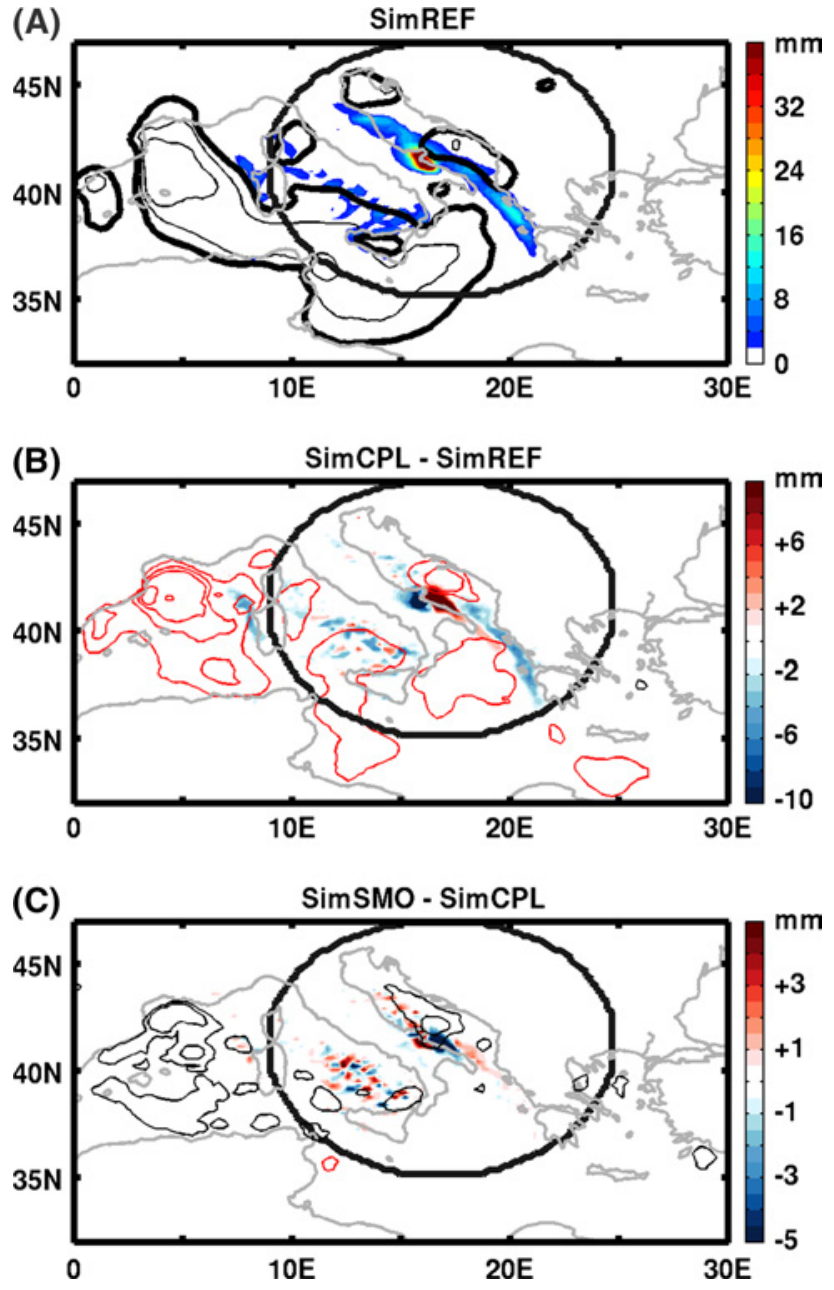

Fig. 3 a Rainfall (in color) and evaporation (in black contour; with a $5 \mathrm{~mm} \mathrm{~h}^{-1}$ interval, thick contour stands for values of $10 \mathrm{~mm} \mathrm{~h}^{-1}$ ) of the intense cyclone occurring in 24-25 September 2006 at the timing of its mature stage. The black circle depicts the effective area at the mature stage of the cyclone $\mathbf{b}$ rainfall (in color) and evaporation differences (in contour; with $2 \mathrm{~mm} \mathrm{~h}^{-1}$ interval, red contour stands for negative values and black contour for positive values) between SimCPL and SimREF. $\mathbf{c}$ As in b but for SimSMO minus SimCPL (note that evaporation contour has a $0.5 \mathrm{~mm} \mathrm{~h}^{-1}$ interval)

\section{Cyclogenesis spatio-temporal variability}

In our 20-year climatology we identified and tracked 2805 cyclones in SimREF, 2695 in SimCPL and 2735 in SimSMO. In all simulations the cyclones presented a similar seasonal and inter-annual cycle of occurrence. Indeed, Fig. 4 shows that cyclogenesis presents a minimum in summer and a maximum in winter (Fig. $4 \mathrm{a}$ ), while the cyclones number is fairly distributed over the 20 -year period with about 140 cyclones per year (Fig. 4b). These results come in accordance with previous studies on the climatology of intense Mediterranean cyclones (Trigo et al. 2000; Bartholy
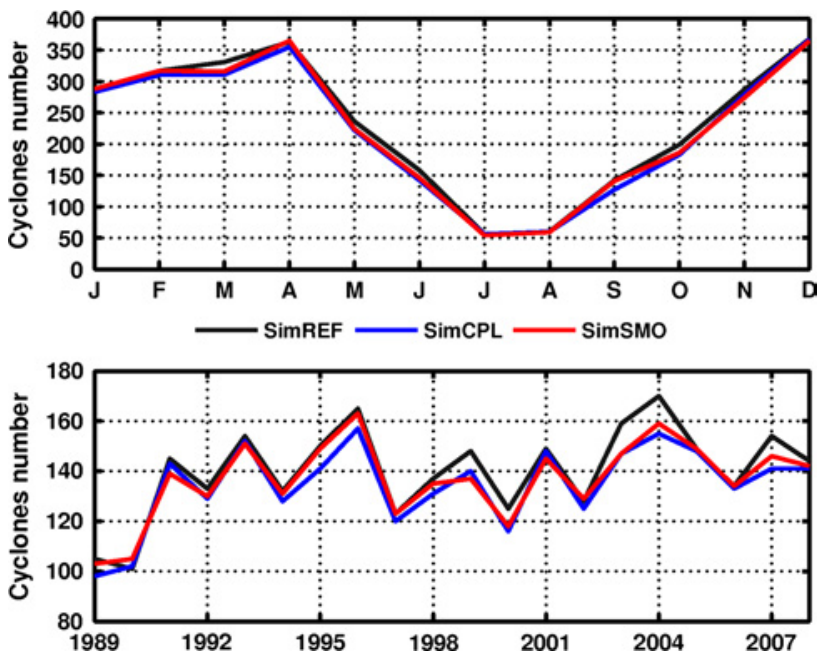

Fig. 4 Seasonal and interannual cycle of cyclogenesis in the Mediterranean

et al. 2009; Campins et al. 2011). The cyclones intensity and life-time is also similar in all simulations. Figure 5 shows that the maximum intensity for most cyclones ranges between $8 \times 10^{-5}$ and $10 \times 10^{-5} \mathrm{~s}^{-1}$ (about $60 \%$ of the total events: 1624 out of 2805 cyclones in SimREF), while the cyclones life-time is typically of less than 2 days with only about $10 \%$ lasting for more than 3 days. More analysis on the physical characteristics of the tracked cyclones (not shown) reveals that the majority of the systems presents a minimum mean sea level pressure of about $1000 \mathrm{hPa}$ (in certain cases pressure lows can reach $\sim 970 \mathrm{hPa}$ ) and a maximum wind speed of the order of $15-20 \mathrm{~m} \mathrm{~s}^{-1}$ over the Sea.

The seasonal frequency of the areas affected by cyclones in SimREF is shown in Fig. 6 and is expressed as the percentage of times per season that each grid point is covered by the cyclones effective area. These results differ by less than $1 \%$ between the simulations. Here we distinguish cyclones according to their intensity bins as shown in Fig. 5a: cyclones with maximum intensity of $8 \times 10^{-5}-10 \times 10^{-5} \mathrm{~s}^{-1}$ (about $60 \%$ of the tracked cyclones), $10 \times 10^{-5}-12 \times 10^{-5} \mathrm{~s}^{-1}$ (about $25 \%$ of the tracked cyclones) and more than $12 \times 10^{-5} \mathrm{~s}^{-1}$ (about $10 \%$ of the tracked cyclones). Figure 6 shows that the cyclones that develop over the Gulf of Lions are among the weakest of our dataset with maximum intensity inferior to $10 \times 10^{-5} \mathrm{~s}^{-1}$. On the other hand, the strongest cyclones of our dataset (with maximum intensity of more than $12 \times 10^{-5} \mathrm{~s}^{-1}$ ) tend to develop over the central Mediterranean Sea, especially in winter. In autumn and spring, most cyclones develop over the Western Mediterranean and over Northwestern Africa, close to the Atlas Mountain. 
Fig. 5 Histograms of: a cyclones maximum intensity in terms of relative vorticity (bin width is $2 \times 10^{-5} \mathrm{~s}^{-1}$ ), b cyclones life-time (bin width is 1 day)

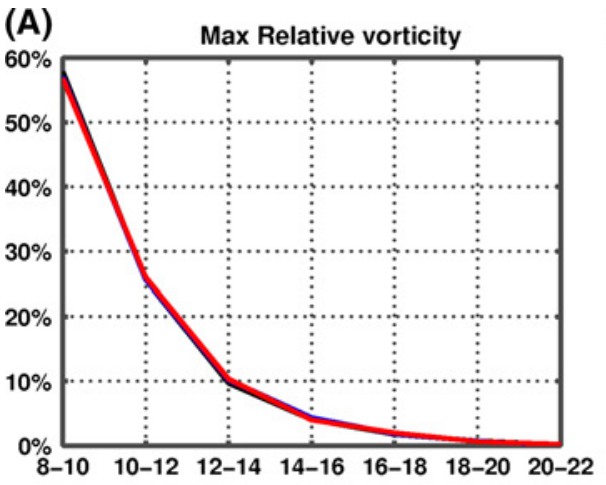

$\left(\times 10^{-5} \mathrm{~s}^{-1}\right)$
(B)

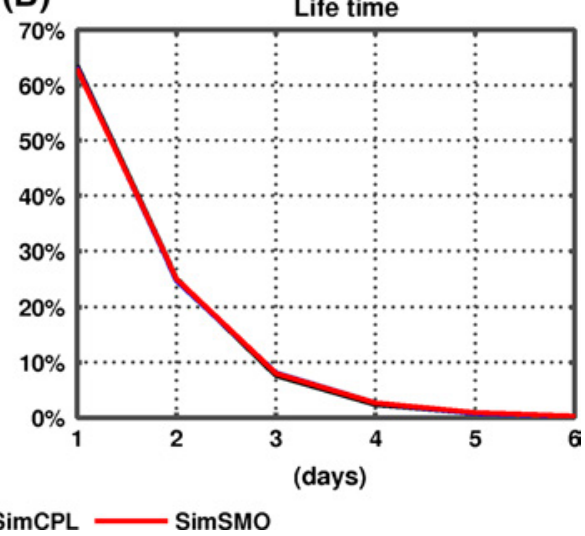

In accordance with Fig. 4, the minimum of cyclogenesis occurrence is observed in summer, with few cyclones developing over the Gulf of Lions and over Northwestern Africa, both corresponding to weak cyclones of intensity lower than $10 \times 10^{-5} \mathrm{~s}^{-1}$. It is noteworthy that in winter, only the strongest cyclones present a clearer center over the central Mediterranean (Fig. 6, in yellow contours), implying that it is mostly the weakest cyclones of our dataset (Fig. 6, in color) that develop over the Gulf of Lions. In fact, the Gulf of Lions presents large cyclonic activity whatever the season, mostly due to orographic lows and the potential vorticity positive anomalies created at the western flank of the Alps (Trigo et al. 2002; Flamant et al. 2004; Drobinski et al. 2005).

All three simulations present a similar number of cyclones, of similar intensities and with a similar frequency of cyclone influence areas per season. This is not surprising since intense cyclogenesis in the region is mainly due to large scale forcings and in particular due to potential vorticity streamers originating from the Polar Jet (Fita et al. 2006, 2007; Chaboureau et al. 2012; Flaounas et al. 2014a). These potential vorticity streamers are identically introduced in the Mediterranean domain of all simulations through the nudging with ERA-Interim atmospheric conditions and consequently the "same" intense cyclones are expected to occur in all simulations. However, close inspection of the tracks characteristics of these "same cyclones" might reveal small differences on the cyclones life-time and intensity. These differences are attributed to the different SST forcings to the atmospheric model simulations.

\section{Cyclone-induced rainfall and evaporation}

The 20-year average seasonal rainfall and evaporation induced by cyclones in SimREF is shown in Fig. 7 (defined at each grid point in $\mathrm{mm} \mathrm{h}^{-1}$ ). Most rainfall due to cyclones takes place in winter and autumn, when cyclogenesis is more frequent (Fig. 4a), with a distinct center over the central Mediterranean. On the other hand, the cyclonesinduced rainfall in spring mostly affects the northern Mediterranean coasts and the northwestern coast of Africa. Finally, in summer, when intense cyclogensis is at a minimum, the rainfall is weak and spatially concentrated over the Gulf of Lions and the foothills of the Western Alps. The cyclones-induced evaporation presents a hot-spot over the Gulf of Lions which is undoubtedly related with the high frequency of occurrence of cyclone over this area, regardless the season. The most intense cyclones that occur over the central Mediterranean might also contribute to the evaporation over the Gulf of Lions due to their large radius of influence (e.g. the January 1995 case; Pytharoulis et al. 2000). The latter is also consistent with the winter and autumn evaporation secondary maximum, observed over the Adriatic Sea, where the most intense cyclones of our dataset tend to develop (Fig. 6).

In addition to the total seasonal rainfall due to cyclones, Fig. 7 also shows the relative contribution of cyclones to the seasonal totals of rainfall and evaporation in SimREF (differences between the simulations are small). Results show that the cyclone-induced rainfall in winter represents more than $50 \%$ of the total rainfall over a large part of the Mediterranean Sea, while in the central Mediterranean the cyclone's contribution may reach $65 \%$. This comes in fair agreement with Hawcroft et al. (2012) who show that cyclones contribute to the total rainfall over the central Mediterranean by more than $70 \%$. On the other hand, in spring, the areas where the cyclone-induced rainfall contributes by more than $50 \%$ to the seasonal total (heavy blue contour in Fig. 7) seem to concentrate more over the western and central Mediterranean. The latter is consistent with the seasonal maximum of cyclone occurrence in the region (Fig. 6) and comes in agreement with previous studies on the areas favorable for cyclogenesis (e.g. Trigo et al. 2002). Compared to winter and spring, the cyclone contribution to rainfall becomes weaker in autumn, being of the order of 

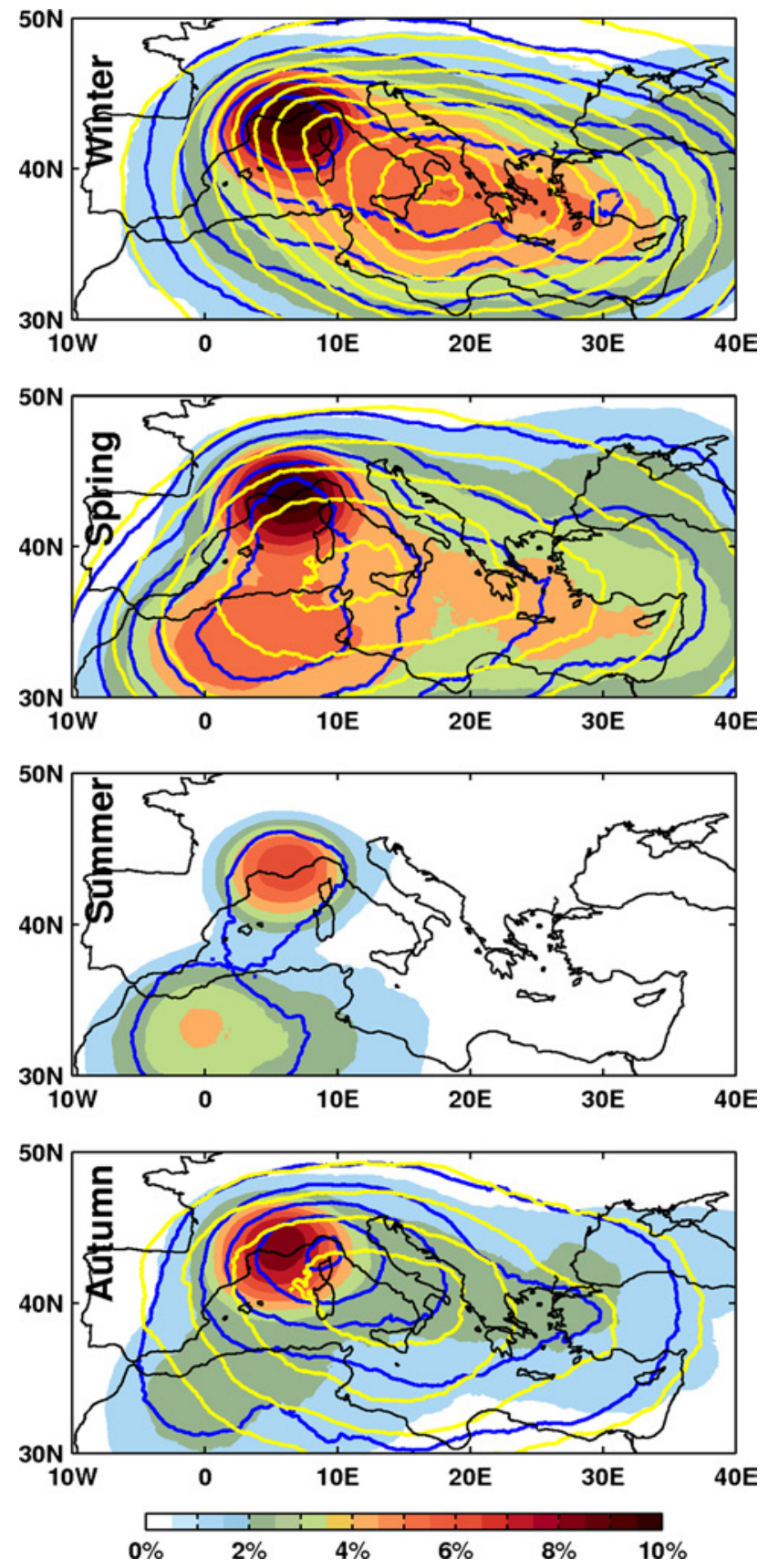

Fig. 6 Seasonal frequency of areas affected by cyclones for SimREF, for cyclones with intensity of $8-10 \times 10^{-5} \mathrm{~s}^{-1}$ (in color), for cyclones with intensity of $10-12 \times 10^{-5} \mathrm{~s}^{-1}$ (blue line contours starting from 1 with $1 \%$ of interval) and for cyclones with intensity of more than $12 \times 10^{-5} \mathrm{~s}^{-1}$ (yellow line contours starting from 1 with $1 \%$ of interval)

25-50\% all over the Mediterranean, while in summer, the cyclones contribute significantly to rainfall only over the Gulf of Lions and the Gibraltar strait. In contrast with rainfall, the cyclone-induced evaporation does not contribute as much to the seasonal totals. Indeed, the $25 \%$ threshold on the contribution of cyclones to evaporation is exceeded mostly over the Gulf of Lions, where cyclones are more frequent throughout the year.

In order to assess the SST impact on the seasonal averages of cyclone-induced rainfall and evaporation, Fig. 8 shows the differences between SimCPL and SimREF and between SimCPL and SimSMO. Comparing SimCPL and SimREF simulations, we quantify the impact of the SST differences on rainfall and evaporation, while the comparison of SimCPL and SimSMO simulations allows the quantification of the impact of intense and fast air-sea interactions on cyclone-induced rainfall and evaporation. In SimCPL, the evaporation and rainfall are significantly enhanced during winter over the Ionian and Adriatic Sea (approximately 20-25\% larger in SimCPL than in Sim$\mathrm{REF})$. A priori, this is a counter intuitive result since SSTs are expected to fall due to upwelling/mixing and surface heat loss caused by the cyclone high-speed winds in the SimCPL simulation. However, as in Sanna et al. (2013), the SimCPL presents a positive climatological bias of SSTs over the central Mediterranean (Fig. 1) which enhances evaporation and thus increases rainfall with respect to SimREF. In fact, rainfall and evaporation differences between SimCPL and SimREF in Fig. 8 are concomitant with the SST differences in Fig. 1. A similar result was found by Sanna et al. (2013) who compared Mediterranean cyclones occurring in two simulations: one performed with a coupled atmospheric-oceanic model and another simulation performed by solely the atmospheric model. Their results also show a positive SST bias over the central Mediterranean associated with a positive rainfall difference between their coupled and uncoupled simulation.

Due to the SST climatological bias between SimCPL and SimREF, the effect of rapid air-sea interactions can only be investigated with SimSMO simulation. In SimSMO, the temporal filtering operation suppresses the fast SST variability. For cyclones, this implies that the SST cooling induced by the strong winds in the cyclones is absent in SimSMO. Indeed, the comparison between SimCPL and SimSMO for both rainfall and evaporation reveals only negative differences, regardless the season and the affected areas. This is due to the fact that evaporation (and therefore also rainfall) in SimSMO is slightly larger than in SimCPL due to the smoothing effect on SST cooling. Furthermore, Fig. 8 shows that in SimCPL, the autumn rainfall and evaporation are decreased over the Gulf of Lions by about $30 \%$. This is mostly due to cyclogenesis in the lee of the Alps, which affects the Western Mediterranean through the strong Mistral winds, often exceeding 20-30 $\mathrm{m} \mathrm{s}^{-1}$ (Flamant et al. 2004; Guénard et al. 2005, 2006) and cooling the SSTs in the region due to surface oceanic heat loss and mixing/upwelling effects (Lebeaupin Brossier and Drobinski 2009; Lebeaupin Brossier et al. 2012). 

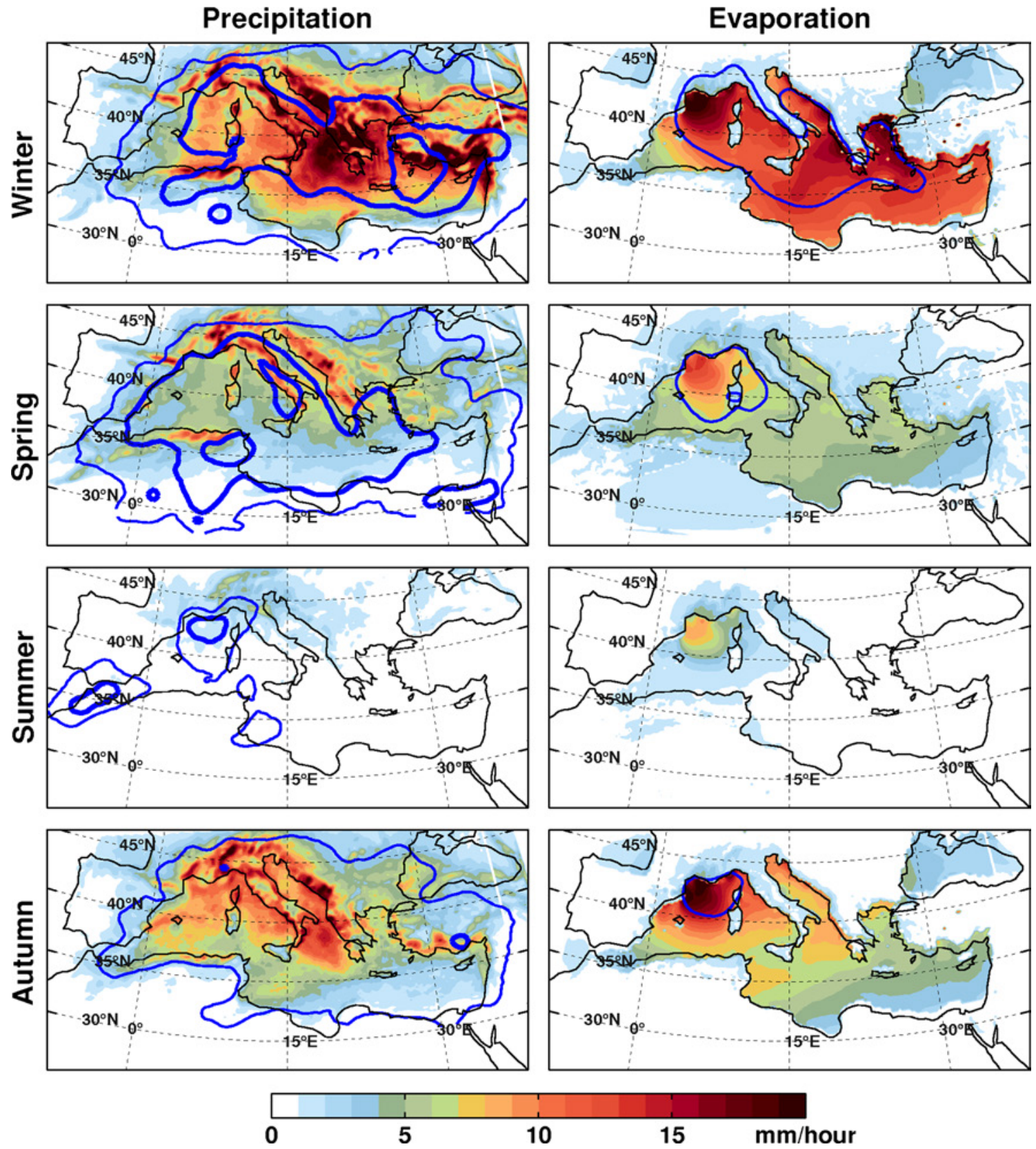

15

\section{$\mathrm{mm} /$ hour}

Fig. 7 Total seasonal cyclone induced rainfall and evaporation in SimREF (in color, in $\mathrm{mm} \mathrm{h}^{-1}$ ) due to the detected cyclones. Blue line contours denote the areas where cyclonic rainfall or evaporation over-

Figure 9 shows the percentage of rainfall and evaporation extremes associated with cyclones in the region. We define extremes as the 95th percentile of the total outputs of rainfall and evaporation, at each grid point of the model, for the whole 20-year period (only non-zero values are considered for rainfall). In accordance with Jansa et al. (2001) and Iordanidou et al. (2014), our results show that more than $70 \%$ of the total rainfall extremes are associated with a cyclone, particularly over the Gulf of Lions, the Aegean pass the $25 \%$ (thin blue line) and $50 \%$ (thick blue line) of the total rainfall or evaporation

Sea and Cyprus. It is noteworthy, that no more than $20 \%$ of extreme rainfall is due to cyclones over the Northern Mediterranean coasts. This is consistent with the fact that intense cyclogenesis in the region occurs mainly in winter (seasonal limitations) and mainly over the sea (spatial limitation). In contrast with rainfall, cyclones contribute by $75 \%$ to extreme evaporation only over the Gulf of Lions, while their contribution is about $40-50 \%$ over the central Mediterranean Sea. Over the Eastern Mediterranean, the 

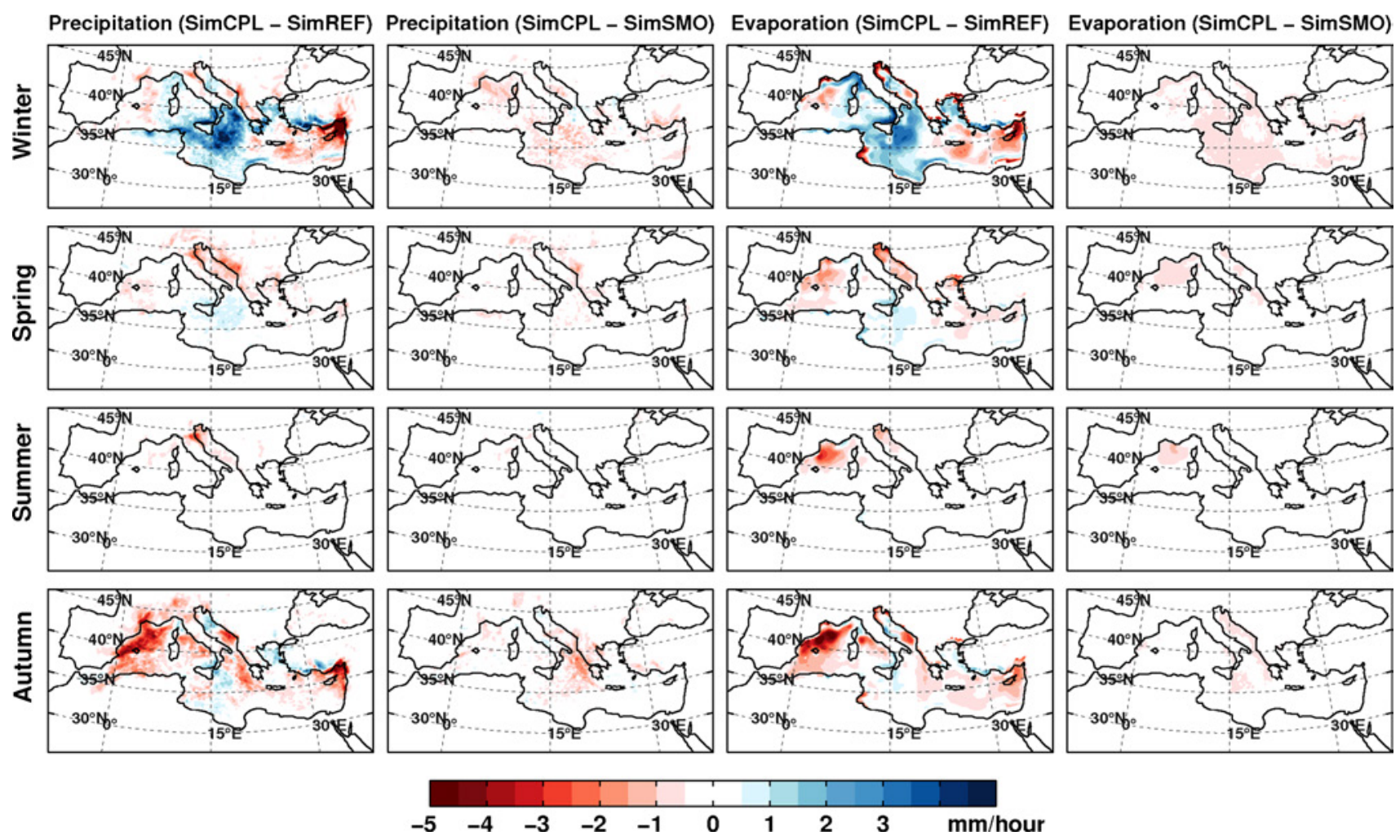

Fig. 8 As in Fig. 7 but showing differences between SimCPL and SimREF and between SimCPL and SimSMO

cyclones contribute to extreme evaporation by no more than 30-40\%, suggesting that evaporation extremes in this region are provoked by other weather systems, such as the Etesian (summer north wind over the Aegean Sea).

\section{Cyclones contribution to the Mediterranean Sea freshwater fluxes}

Figure 10 shows the total seasonal (top panel) and interannual (bottom panel) variability of evaporation (E), rainfall $(\mathrm{P})$ and of their difference $(\mathrm{E}-\mathrm{P})$ due to cyclones and due to other weather systems. In accordance with previous studies based on observations and reanalyses on freshwater fluxes over the Mediterranean (e.g. Mariotti et al. 2002; Romanou et al. 2010; Dubois et al. 2012), the seasonal cycle of $\mathrm{E}-\mathrm{P}$ is well captured by all three simulations with a minimum during spring and a maximum in early autumn. This result is also consistent with other coupled simulations (Dubois et al. 2012). The interannual variability is low and $\mathrm{E}-\mathrm{P}$ is quasi-constant, of the order of $1000 \mathrm{~mm}$ year $^{-1}$. This amount corresponds to a rather large value with respect to observations and reanalyses. A slightly lower value for $\mathrm{E}-\mathrm{P}$ is simulated in SimCPL $\left(\sim 960 \mathrm{~mm}\right.$ year $\left.^{-1}\right)$ which is closer to the observations and reanalyses. Figure 10 reveals that such a correction is mainly due to weaker evaporation (middle panels), especially during summer and early autumn.

Cyclones seasonal and inter-annual contributions to rainfall and evaporation are correlated with cyclone occurrences (Fig. 4). As a result, the cyclone contribution to rainfall presents a minimum during spring and summer and a maximum during autumn and winter. Accordingly, the inter-annual trend of the cyclone-induced rainfall and evaporation is quasi-constant. Figure 10 shows that cyclone-induced rainfall and evaporation equally contribute to $\mathrm{E}-\mathrm{P}$ (middle and right bottom panels), compensating each other. This result suggests that Mediterranean cyclones tend to precipitate the water that is evaporated over the Mediterranean Sea. If such a direct water recycling was performed by the cyclones, then, the hot-spots of both rainfall and evaporation would be collocated in Fig. 7, regardless the season. However, this is not rigorously the case as discussed in Sect. 4. Nevertheless, what is evaporated by cyclones is recycled in precipitation locally or away from the region of maximum cyclone-induced evaporation. In fact, Sodemann and Stohl (2013) show that water sources for major rainfall events in extratropical storms might be located away from the cyclone centers, while Duffourg and Ducrocq (2011) and Winschall et al. (2012) showed that a major water vapor source for case studies of heavy rainfall over the western Mediterranean are located 
Fig. 9 The cyclones contribution to the extremes of precipitation and evaporation in SimREF, defined as the percentage of cyclonic rainfall and evaporation to the 95 th percentile of the total rainfall and precipitation
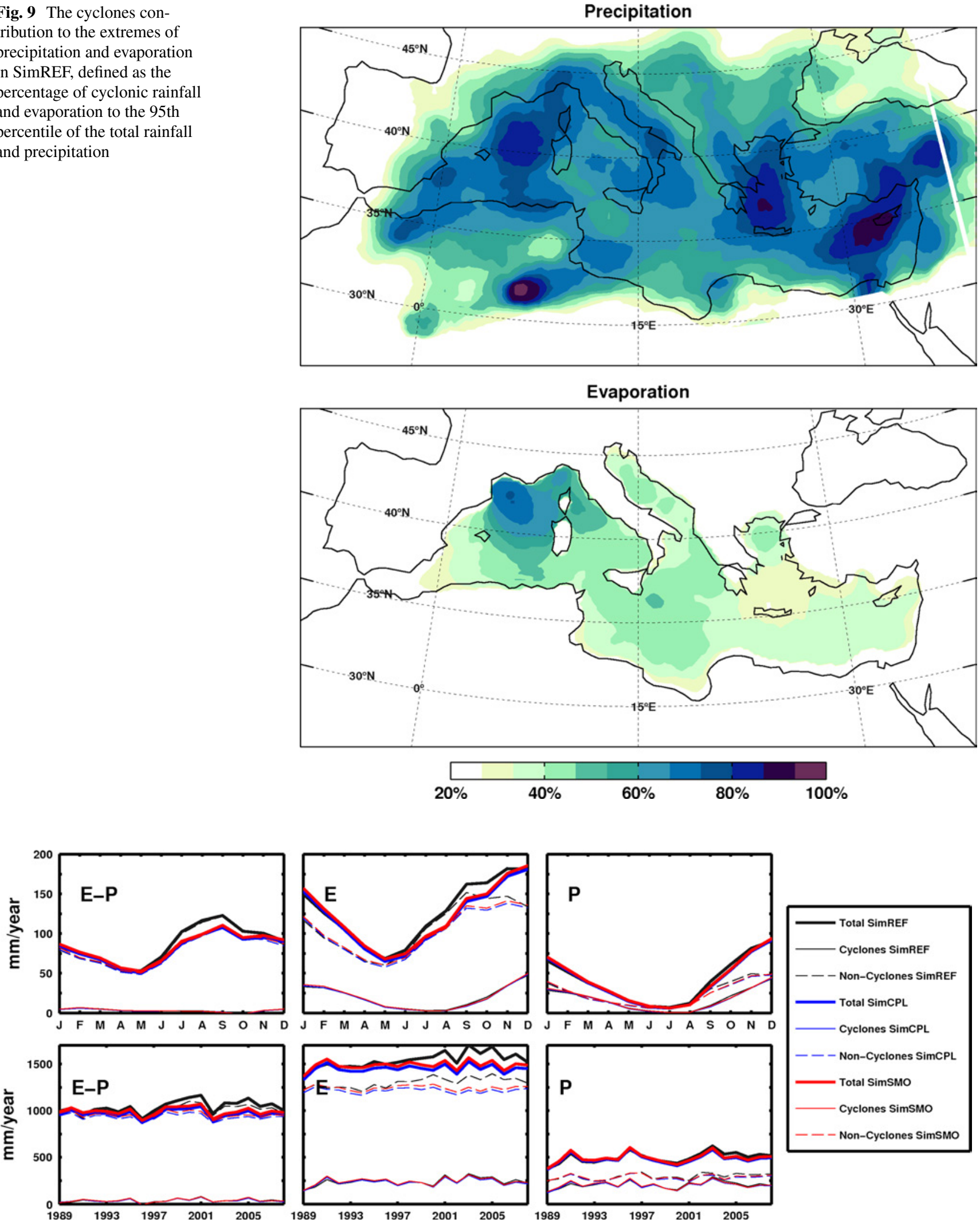

Fig. 10 Atmosphere-induced freshwater budget of the Mediterranean Sea $(\mathrm{E}-\mathrm{P})$, Evaporation $(\mathrm{E})$ and Precipitation $(\mathrm{P})$ : seasonal (top panels) and annual (bottom panels) cycle. Freshwater fluxes are decomposed according to the contribution of the detected cyclones and according to the residual (non-cyclonic conditions), for all three simulations SimREF, SimCPL and SimSMO 
over the Atlantic Ocean. Consequently, intense cyclones may act as an intermediary for importing freshwater to the Mediterranean Sea and hence, under favorable large scale meteorological conditions, they could play the role of a mechanism for a net source of water to both the Mediterranean atmosphere and Sea. Figure 10 shows that the cyclone contribution to the total freshwater fluxes in the Mediterranean is rather weak (Fig. 10 left panels). However, this result could be subject to some variability, depending on the criteria applied to the cyclones considered for this study (such as the intensity threshold, or 1-day long tracks).

It is noteworthy that the cyclone-induced rainfall contributes more than $50 \%$ to the total autumn and winter rainfall, mainly due to extreme precipitations (Figs. 7, 10). On the other hand, the cyclones contribution to evaporation is lower and represents roughly $25 \%$ of the total evaporation (Figs. 7, 10 middle panels). The differences between SimREF, SimCPL and SimSMO are small (especially between SimCPL and SimSMO), suggesting that the local positive and negative anomalies in rainfall and evaporation, as shown in Fig. 8, compensate on average over the whole basin. Such compensation becomes weaker when comparing SimCPL and SimSMO since their differences in evaporation and rainfall are always negative.

\section{Discussion and conclusion}

In this article we analyze and present the relative contribution of Mediterranean cyclones to the Mediterranean Sea freshwater fluxes. In our analysis we include all cyclones reaching a maximum intensity of at least $8 \times 10^{-5} \mathrm{~s}^{-1}$ and lasting more than $24 \mathrm{~h}$. In order to isolate the cyclone contribution to evaporation and rainfall, we use a diagnostic tool which measures the frequency and the spatial coverage of cyclone-affected areas. The results reveal a seasonal cycle of cyclone occurrences over the Mediterranean Sea that presents a minimum in summer and a maximum in winter. Accordingly, the cyclone-induced rainfall is stronger in winter and autumn, with a distinct center over the central Mediterranean where the most intense cyclones of our dataset tend to develop. On the other hand, cycloneinduced evaporation presents a permanent "hot-spot" over the Gulf of Lions, where cyclones and strong winds are frequent regardless the season. Our results show that the freshwater fluxes budget $(\mathrm{E}-\mathrm{P})$ over the Mediterranean Sea is rather insensitive to the Mediterranean cyclones due to the balance between cyclone-induced evaporation and rainfall. Consequently, the long term evaporation due to cyclones, caused by the strong surface winds, seems to be directly recycled by the cyclones in the form of precipitation. Such a recycling mechanism may explain why the SST difference between the SimREF and SimCPL does not have a large impact in the basin's averaged freshwater $(\mathrm{E}-\mathrm{P})$, compensating deficits/increases in evaporation with deficits/increases in rainfall, respectively. Averaged over the whole Mediterranean Sea, the SST difference between SimCPL and SimREF is about zero although it shows important regional differences (see Lebeaupin Brossier et al. 2014). In all, rainfall due to cyclones represents approximately $50 \%$ of the annual total over the Mediterranean Sea and corresponds generally to extreme precipitation events. Evaporation due to cyclones represents approximately $25 \%$ of the annual total over the Mediterranean Sea. Fast air-sea interaction processes that are present in the coupled simulations induce cooler SSTs along the cyclone track thus reducing evaporation and precipitation with respect to simulation where these effects are not accounted for.

We extended the results of Sanna et al. (2013) who investigated the sensitivity of the climatology of cyclones and cyclones-induced rainfall to explicitly resolved airsea interactions in regional modeling. Their results suggested that rainfall differences between a coupled and an uncoupled simulation were associated with differences on the cyclone number, detected in the two simulations. However, here we showed that rainfall differences due to cyclones in SimCPL and SimREF were mostly associated with SST differences between the SimREF and SimCPL. In addition, we complemented the results of Lebeaupin Brossier et al. (2014) who analyzed the evaporation and rainfall extremes contribution to the MSWB. In our study, the number of cyclones remained rather insensitive when comparing SimREF, SimCPL and SimSMO. This should not come as a surprise; the strong dependence of intense cyclogenesis on the large scale conditions makes it highly unlikely to consider sea-atmosphere heat exchanges as a major cyclogenesis mechanism in the region (Flaounas et al. 2014a). We showed that explicitly resolved SST had an impact on both evaporation and rainfall associated with the most intense cyclones occurring over the Ionian and Adriatic Sea. This confirms an earlier study by Tous et al. (2013) who showed that evaporation plays a crucial role on the quantity of precipitable water during the development of three Mediterranean intense cyclones (their Figs. 8, 9, 10).

Here we provided a climatological insight on the contribution of intense cyclones to the Mediterranean climate. In accordance with previous studies, we showed that Mediterranean cyclones are strongly associated with extreme rainfall (e.g. Jansa et al. 2001). In order to better understand the variability of the regional climate and its extremes it is important to better understand the Mediterranean cyclone dynamical processes. It is thus clear that explicitly resolving air-sea interactions is of interest for a better representation of the cyclone dynamics and their 
impact on the regional water budget. Indeed, several studies have highlighted the importance of fine-scale coupled air-sea interactions on the dynamical evolution of synoptic systems around the globe (e.g. Vianna et al. 2010; Chambers et al. 2014). In particular for the Mediterranean region, the detailed representation of such processes is necessary in order to well evaluate their impact on the representation of the Mediterranean Sea water and heat budget in future climate projections (Dubois et al. 2012). In a future study, we aim to work in a climatological framework as in the present paper but linking the cyclones water budget with their dynamics. Such an analysis will be conducted in the context of the current state of the art in atmospheric modeling, where the use of coupled simulations has to offer a better and deeper understanding of high frequency dynamical processes which take place during the development of intense Mediterranean cyclones.

Acknowledgments This work is a contribution to the HYdrological cycle in the Mediterranean EXperiment $(\mathrm{HyMeX})$ programme through INSU-MISTRALS support and the Mediterranean region COordinated Regional climate Downscaling EXperiment (Med-CORDEX) programme. This research was supported by the IPSL group for regional climate and environmental studies, with granted access to the HPC resources of IDRIS under allocation 2011 (Project Number 010227). EF was supported by the IMPACT2C program (funded by the European Union Seventh Framework Programme, FP7/20072013 under the Grant agreement 282746).

\section{References}

Akhtar N, Brauch J, Dobler A, Béranger K, Ahrens B (2014) Medicanes in an ocean-atmosphere coupled regional climate model. Nat Hazards Earth Syst Sci Discuss 2:2117-2149. doi:10.5194/ nhessd-2-2117-2014

Bartholy J, Pongracz R, Pattantyus-Abraham M (2009) Analyzing the genesis, intensity and tracks of western Mediterranean cyclones. Theor Appl Climatol 96:133-144

Berthou S, Mailler S, Drobinski P, Arsouze T, Bastin S, Béranger K, Lebeaupin Brossier C (2014) Sensitivity of an intense rain event between an atmosphere-only and an atmosphere-ocean coupled model: 19 september 1996. J R Meteorol Soc, Quart. doi:10.1002/qj.2355

Beuvier J, Béranger K, Lebeaupin Brossier C, Somot S, Sevault F, Drillet Y, Bourdallé-Badie R, Ferry N, Levier B, Lyard F (2012) Spreading of the Western Mediterranean Deep Water after winter 2005: time-scales and deep cyclone transport. J Geophys Res 117:C07022. doi:10.1029/2011JC007679

Campins J, Genovés A, Picornell MA, Jansà A (2011) Climatology of Mediterranean cyclones using the ERA-40 dataset. Int J Climatol 31:1596-1614. doi:10.1002/joc.2183

Catto JL, Pfahl S (2013) The importance of fronts for extreme precipitation. J Geophys Res Atmos 118:10791-10801. doi:10.1002/ jgrd.50852

Chaboureau JP, Pantillon F, Lambert D, Richard E, Claud C (2012) Tropical transition of a Mediterranean storm by jet crossing. Q J R Meteorol Soc 138:596-611

Chambers CRS, Brassington GB, Simmonds I, Walsh K (2014) Precipitation changes due to the introduction of eddy-resolved sea surface temperatures into simulations of the "Pasha Bulker"
Australian east coast low of June 2007. Meteorol Atmos Phys $125: 1-15$

Claud C, Alhammoud B, Funatsu BM, Lebeuaupin-Brossier C, Chaboureau JP, Béranger K, Drobinski P (2012) A high resolution climatology of precipitation and deep convection over the Mediterranean region from operational satellite microwave data: development and application to the evaluation of model uncertainties. Nat Hazards Earth Syst Sci 12:785-798

Clough SA, Shephard MW, Mlawer EJ, Delamere JS, Iacono MJ, Cady-Pereira K, Boukabara S, Brown PD (2005) Atmospheric radiative transfer modeling: a summary of the AER codes. J Quant Spectrosc Radiat Transf 91:233-244

Davolio S, Miglietta MM, Moscatello A, Pacifico F, Buzzi A, Rotunno R (2009) Numerical forecast and analysis of a tropical-like cyclone in the Ionian Sea. Nat Hazards Earth Syst Sci 9:551-562

Dee DP, Uppala SM, Simmons AJ, Berrisford P, Poli P, Kobayashi S, Andrae U, Balmaseda MA, Balsamo G, Bauer P, Bechtold P, Beljaars ACM, van de Berg L, Bidlot J, Bormann N, Delsol C, Dragani R, Fuentes M, Geer AJ, Haimberger L, Healy SB, Hersbach H, Hólm EV, Isaksen L, Kållberg P, Köhler M, Matricardi M, McNally AP, Monge-Sanz BM, Morcrette JJ, Park BK, Peubey C, de Rosnay P, Tavolato C, Thépaut JN, Vitart F (2011) The ERA-Interim reanalysis: configuration and performance of the data assimilation system. Q J R Meteorol Soc 137:553-597. doi:10.1002/qj.828

Di Luca A, Flaounas E, Drobinski P, Lebeaupin Brossier C (2014) The atmospheric component of the Mediterranean Sea water budget in a WRF physics ensemble and observations. Clim Dyn 43:2349-2375. doi:10.1007/s00382-014-2058-z

Drobinski P, Bastin S, Guénard V, Caccia JL, Dabas AM, Delville P, Protat A, Reitebuch O, Werner C (2005) Summer mistral at the exit of the Rhône valley. Q J R Meteorol Soc 131:353-375

Drobinski P, Anav A, Lebeaupin Brossier C, Samson G, Stéfanon M, Bastin S, Baklouti M, Béranger K, Beuvier J, Bourdallé-Badie R, Coquart L, D'Andrea F, De Noblet-Ducoudré N, Diaz F, Dutay JC, Ethe C, Foujols MA, Khvorostyanov D, Madec G, Mancip M, Masson S, Menut L, Palmieri J, Polcher J, Turquety S, Valcke S, Viovy N (2012) Modelling the Regional Coupled Earth system (MORCE): application to process and climate studies in vulnerable regions. Env Model Softw 35:1-18

Drobinski P, Ducrocq V, Alpert P, Anagnostou E, Béranger K, Borga M, Braud I, Chanzy A, Davolio S, Delrieu G, Estournel C, Filali Boubrahmi N, Font J, Grubisic V, Gualdi S, Homar V, Ivancan-Picek B, Kottmeier C, Kotroni V, Lagouvardos K, Lionello P, Llasat MC, Ludwig W, Lutoff C, Mariotti A, Richard E, Romero R, Rotunno R, Roussot O, Ruin I, Somot S, Taupier-Letage I, Tintore J, Uijlenhoet R, Wernli H (2013) HyMeX: a 10-year multidisciplinary program on the Mediterranean water cycle. Bull Am Meteorol Soc 95:1063-1082. doi:10.1175/bams-d-12-00242.1

Drobinski P, Ducrocq V, Alpert P, Anagnostou E, Branger K, Borga M, Braud I, Chanzy A, Davolio S, Delrieu G, Estournel C, Filali Boubrahmi N, Font J, Grubisic V, Gualdi S, Homar V, IvancanPicek B, Kottmeier C, Kotroni V, Lagouvardos K, Lionello P, Llasat M, Ludwig W, Lutoff C, Mariotti A, Richard E, Romero R, Rotunno R, Roussot O, Ruin I, Somot S, Taupier-Letage I, Tintore J, Uijlenhoet R, Wernli H (2014) HyMeX, a 10-year multidisciplinary program on the Mediterranean water cycle. Bull Am Meteorol Soc 95:1063-1082

Dubois C, Somot S, Calmanti S, Carillo A, Déqué M, Dell'Aquilla A, Elizalde A, Gualdi S, Jacob D, L'Hévéder B (2012) Future projections of the surface heat and water budgets of the Mediterranean Sea in an ensemble of coupled atmosphere-ocean regional climate models. Clim Dyn 39:1859-1884. doi:10.1007/ s00382-011-1261-4.F

Duffourg F, Ducrocq V (2011) Origin of the moisture feeding the heavy precipitating systems over Southeastern France. 
Nat Hazards Earth Syst Sci 11:1163-1178. doi:10.5194/ nhess-11-1163-2011

Emanuel K (2005) Genesis and maintenance of "mediterranean hurricanes". Adv Geosci 2:217-220

Fita L, Romero R, Ramis C (2006) Intercomparison of intense cyclogenesis events over the Mediterranean basin based on baroclinic and diabatic influences. Adv Geosci 7:333-342. doi:10.5194/ adgeo-7-333-2006

Fita L, Romero R, Luque A, Emanuel K, Ramis C (2007) Analysis of the environments of seven Mediterranean tropical-like storms using an axisymmetric, nonhydrostatic, cloud resolving model. Nat Hazards Earth Syst Sci 7:41-56

Flamant C, Richard E, Schär C, Rotunno R, Nance L, Sprenger M, Benoit R (2004) The wake south of the Alps: dynamics and structure of the lee-side flow and secondary potential vorticity banners. Q J R Meteorol Soc 130:1275-1303

Flaounas E, Drobinski P, Bastin S (2013) Dynamical downscaling of IPSL-CM5 CMIP5 historical simulations over the Mediterranean: benefits on the representation of regional surface winds and cyclogenesis. Clim Dyn 40(9-10):2497-2513

Flaounas E, Raveh-Rubin S, Wernli H, Drobinski P, Bastin S (2014a) The dynamical structure of intense Mediterranean cyclones. Clim Dyn. doi:10.1007/s00382-014-2330-21-17

Flaounas E, Kotroni V, Lagouvardos K, Flaounas I (2014b) CycloTRACK (v1. 0)-tracking winter extratropical cyclones based on relative vorticity: sensitivity to data filtering and other relevant parameters. Geosci Model Dev 7(4):1841-1853

Flocas HA, Simmonds I, Kouroutzoglou J, Keay K, Hatzaki M, Bricolas V, Asimakopoulos D (2010) On cyclonic tracks over the eastern Mediterranean. J Clim 23(19):5243-5257

Guénard V, Drobinski P, Caccia JL, Campistron B, Bénech B (2005) An observational study of the mesoscale mistral dynamics. Bound Layer Meteorol 115:263-288

Guénard V, Drobinski P, Caccia JL, Tedeschi G, Currier P (2006) Dynamics of the MAP IOP-15 severe mistral event: observations and high-resolution numerical simulations. Q J R Meteorol Soc 132:757-778

Hawcroft MK, Shaffrey LC, Hodges KI, Dacre HF (2012) How much northern hemisphere precipitation is associated with extratropcial cyclones? Geophys Res Lett. doi:10.1029/2012GL053866

Homar V, Romero R, Stensrud DJ, Ramis C, Alonso S (2003) Numerical diagnosis of a small, quasi-tropical cyclone over the western Mediterranean: dynamical versus boundary factors. Q J R Meteorol Soc 129:1469-1490. doi:10.1256/qj.01.91

Hong SY, Dudhia J, Chen SH (2004) A revised approach to ice microphysical processes for the bulk parameterization of clouds and precipitation. Mon Weather Rev 132:103-120

Iordanidou V, Koutroulis AG, Tsanis IK (2014) A probabilistic rain diagnostic model based on cyclone statistical analysis. Adv Meteorol. doi:10.1155/2014/498020

Jansà A, Genovés A, Picornell MA, Campins J, Riosalido R, Carretero O (2001) Western Mediterranean cyclones and heavy rain. Part 2: statistical approach. Meteorol Appl 8:43-56

Kain JS (2004) The Kain-Fritsch convective parameterization: an update. J Appl Meteorol 43:170-181

Katsafados P, Mavromatidis E, Papadopoulos A, Pytharoulis I (2011) Numerical simulation of a deep Mediterranean storm and its sensitivity on sea surface temperature. Nat Hazards Earth Syst Sci 11:1233-1246. doi:10.5194/nhess-11-1233-2011

Lebeaupin Brossier C, Drobinski P (2009) Numerical high-resolution airsea coupling over the Gulf of Lions during two tramontane/mistral events. J Geophys Res 114:D10110. doi:10.1029/2008JD011601

Lebeaupin Brossier C, Béranger K, Deltel C, Drobinski P (2011) The Mediterranean Sea response to different space-time resolution atmospheric forcings using perpetual mode sensitivity simulations. Ocean Model 36(1-2):1-25
Lebeaupin Brossier C, Béranger K, Drobinski P (2012) Sensitivity of the North-Western Mediterranean Coastal and thermohaline circulations as simulated by the $1 / 12^{\circ}$ Resolution Oceanic Model NEMO-MED12 to the space-time resolution of the atmospheric forcing. Ocean Model 43-44:94-107

Lebeaupin Brossier C, Drobinski P, Béranger K, Bastin S, Orain F (2013) Ocean memory effect on the dynamics of coastal heavy precipitation preceded by a mistral event in the northwestern Mediterranean. Q J R Meteorol Soc 139:1583-1597. doi:10.1002/qj.2049

Lebeaupin Brossier C, Bastin S, Béranger K, Drobinski P (2014) Regional mesoscale air-sea coupling impacts and extreme meteorological events role on the Mediterranean Sea water budget. Clim Dyn. doi:10.1007/s00382-014-2252-z

Mariotti A (2010) Recent changes in the Mediterranean water cycle: a pathway toward long-term regional hydroclimatic change? J Clim 23:1513-1525

Mariotti A, Struglia MV, Zeng N, Lau KM (2002) The hydrological cycle in the Mediterranean region and implications for the water budget of the Mediterranean Sea. J Clim 15:1674-1690

Marshall J, Schott F (1999) Open-ocean convection: observations, theory, and models. Rev Geophys 37(1):1-64

Miglietta MM, Moscatello A, Conte D, Mannarini G, Lacorata G, Rotunno R (2011) Numerical analysis of a Mediterranean 'hurricane' over south-eastern Italy: sensitivity experiments to sea surface temperature. Atmos Res 101:412-426

Millot C, Taupier-Letage I (2005) Circulation in the Mediterranean Sea. In: 897 the handbook of environmental chemistry, Vol 5K. Springer, pp 29-66, 898. doi:10.1007/b107143

Nissen KM, Leckebusch GC, Pinto JG, Renggli D, Ulbrich S, Ulbrich U (2010) Cyclones causing wind storms in the Mediterranean: characteristics, trends and links to large-scale patterns. Nat Hazards Earth Syst Sci 10:1379-1391. doi:10.5194/ nhess-10-1379-2010

Nissen KM, Leckebusch GC, Pinto JG, Ulbrich U (2013) Mediterranean cyclones and windstorms in a changing climate. Reg Environ Change 14:1873-1890. doi:10.1007/s10113-012-0400-8

Omrani H, Drobinski P, Dubos T (2013) Optimal nudging strategies in regional climate modelling: investigation in a big-brother experiment over the European and Mediterranean regions. Clim Dyn 41:2451-2470

Papritz L, Pfahl S, Rudeva I, Simmonds I, Sodemann H, Wernli H (2014) The Role of extratropical cyclones and fronts for Southern Ocean freshwater fluxes. J Clim 27:6205-6224. doi:10.1175/ JCLI-D-13-00409.1

Pfahl S, Madonna E, Boettcher M, Joos H, Wernli H (2014) Warm conveyor belts in the ERA-interim dataset (1979-2010). Part II: moisture origin and relevance for precipitation. J Clim 27:27-40

Pytharoulis I, Craig GC, Ballard SP (2000) The hurricane-like Mediterranean cyclone of January 1995. Meteorol Appl 7:261-279

Romanou A, Tselioudis G, Zerefos CS, Clayson CA, Curry JA, Andersson A (2010) Evaporation-precipitation variability over the Mediterranean and the black seas from satellite and reanalysis estimates. J Clim 23:5268-5287

Romanski J, Romanou A, Bauer M, Tselioudis G (2012) Atmospheric forcing of the Eastern Mediterranean Transient by midlatitude cyclones. Geophys Res Lett 39:L03703. doi:10.1029/2 011GL050298

Ruti PM, Somot S, Giorgi F, Dubois C, Flaounas E, Obermann A, Dell'Aquila A, Pisacane G, Harzallah A, Lombardi E, Ahrens B, Akhtar N, Alias A, Arsouze T, Aznar R, Bastin S, Bartholy $\mathrm{J}$, Béranger K, Beuvier J, Bouffies-Cloché S, Brauch J, Cabos W, Calmanti S, Calvet J-C, Carillo A, Conte D, Coppola E, Dell'Aquila A, Djurdjevic V, Drobinski P, Elizalde-Arellano A, Gaertner M, Galàn P, Gallardo C, Gualdi S, Goncalves M, Jorba O, Jordà G, L'Heveder B, Lebeaupin-Brossier C, Li L, Liguori 
G, Lionello P, Maciàs D, Nabat P, Onol B, Raikovic B, Ramage K, Sevault F, Sannino G, MV Struglia, Sanna A, Torma C, Vervatis V (2015) MED-CORDEX initiative for Mediterranean climate studies. Bull Am Meteorol Soc (under review)

Salameh T, Drobinski P, Dubos T (2010) The effect of indiscriminate nudging time on the large and small scales in regional climate modelling: application to the Mediterranean basin. Q J R Meteorol Soc 136:170-182

Sanchez-Gomez E, Somot S, Josey SA, Dubois C, Elguindi N, Déqué M (2011) Evaluation of Mediterranean Sea water and heat budgets simulated by an ensemble of high resolution regional climate models. Clim Dyn 37(9-10):2067-2086

Sanna A, Lionello P, Gualdi S (2013) Coupled atmosphere ocean climate model simulations in the Mediterranean region: effect of a high-resolution marine model on cyclones and precipitation. Nat Hazards Earth Syst Sci 13:1567-1577. doi:10.5194/ nhess-13-1567-2013

Simmonds I (2000) Size changes over the life of sea level cyclones in the NCEP reanalysis. Mon Weather Rev 128:4118-4125

Skamarock WC, Klemp JB (2008) A time-split nonhydrostatic atmospheric model for weather research and forecasting applications. J Comput Phys 227:3465-3485
Sodemann H, Stohl A (2013) Moisture origin and meridional transport in atmospheric rivers and their association with multiple cyclones. Mon Weather Rev 141:2850-2868

Tous M, Romero R, Ramis C (2013) Surface heat fluxes influence on medicane trajectories and intensification. Atmos Res 123:400-411

Trigo IF, Davies TD, Bigg GR (2000) Decline in Mediterranean rainfall caused by weakening of Mediterranean cyclones. Geophys Res Lett 27:2913-2916

Trigo IF, Bigg GR, Davies TD (2002) Climatology of cyclogenesis mechanisms in the Mediterranean. Mon Weather Rev 130:549-569

Vianna ML, Menezes VV, Pezza AB, Simmonds I (2010) Interactions between Hurricane Catarina (2004) and warm core rings in the South Atlantic Ocean. J Geophys Res 115:C07002. doi:10.1029 /2009JC005974

Winschall A, Pfahl S, Sodemann H, Wernli H (2012) Impact of North Atlantic evaporation hot spots on southern Alpine heavy precipitation events. Q J R Meteorol Soc 138:1245-1258. doi:10.1002/ qj. 987 